\title{
Crystal Structure Modelling of Magnetic Material On Computational Study
}

\author{
Aprilia Dewi Ardiyanti ${ }^{1, *}$, Tanzilal Mustaqim² \\ ${ }^{1}$ Department of Physic, Universitas Negeri Malang, Malang, Indonesia \\ ${ }^{2}$ Department of Informatic, Institut Teknologi Sepuluh Nopember, Surabaya, Indonesia \\ *Corresponding author. Email: apriliadewi379@gmail.com
}

\begin{abstract}
Computational research has been developed recently. One of the research is in the study of material physics. The computational study uses to make a model of the crystal structure which is difficult to do experimentally. In this study, the pymatgen module was used to compute the crystal structure of magnetic materials such as $\mathrm{Fe}_{3} \mathrm{O}_{4}$, $\mathrm{MnFe}_{2} \mathrm{O}_{4}$ and $\mathrm{NiCo}_{2} \mathrm{O}_{4}$. Through the structural submodule, information can be obtained from the input data shift and its primitive structure. The structure of the three magnetic materials is cubic spinal which is following the experimental data. The suitability of computational data and experimental data shows the pymatgen module can work optimally in performing computational modeling of materials.
\end{abstract}

Keywords: Crystal Structure, Magnetic, Modelling, Pymatgen.

\section{INTRODUCTION}

The research of advanced material is growing rapidly through the benefits and usefulness. Nowadays not all of the experiment research can be done in the laboratory because of complexity and constrained by the availability of tools for synthesis [1]. Therefore, a computational approach is needed to make modelling and simulate the material research. Improvement of computer and new concept of computational study possibility to get a novel experiment on computational material science [2].

There are several tools that use for material design or computational such as Open Calphad use for multiphase calculation and thermodynamic, OOF use for analysis microstructure and material Application Programming Interface (API) [3]. Developing of the tools python present the Python Material Genomics library or pymatgen modul.

Pymatgen modul have many advantages because the modul is open platform for researcher and provide set of structure and thermodynamic analysis. Futhermore, pymatgen modul can identify many kinds of data input such as VASP, CIF, OpenBabelformats and Material Project Rest API. Many advantages that provided by pymatgen modul, so this modul can be used for computational material science [4].

In this study, modeling of magnetic materials such as $\mathrm{Fe}_{3} \mathrm{O}_{4}, \mathrm{MnFe}_{2} \mathrm{O}_{4}$ and $\mathrm{NiCo}_{2} \mathrm{O}_{4}$ was carried out using the Pymatgen module. Previous research stated that magnetic materials have a cubic spinel structure [5-7]. This modeling will show the differences between the three material structures. Then it will be compared with experimental data to see the matching between each modelling data.

The structure of a material is important because it can affect the properties of the material. One of the important properties of magnetic materials is their magnetic properties. There are another properties about optic and electronic, this properties can be obtained by knowing band structure [8]. Therefore, the structure of a material is very important to know and identify [9]. This research will be the initial and basic research for use in materials computational science.

\section{METHODS}

Processing of this research using Google Colab provided by Google publicly. Table 1 show data of the research from Crystallographic Input File (CIF) from Crystallography Open Data Base (COD) and American Mineralogist Crystal Structure (AMCSD)

Table 1. Crystallographic Input File

\begin{tabular}{|l|l|}
\hline \multicolumn{1}{|c|}{ Materials } & \multicolumn{1}{c|}{ CIF } \\
\hline $\mathrm{Fe}_{3} \mathrm{O}_{4}$ & AMCSD 0000945 \\
\hline $\mathrm{MnFe}_{2} \mathrm{O}_{4}$ & COD 1010131 \\
\hline $\mathrm{NiCo}_{2} \mathrm{O}_{4}$ & COD 5000120 \\
\hline
\end{tabular}


The first procedure of this research is the installation of the pymatgen module in Google Collab. After the installation is complete, the next process is input of the Element, Molecule, Lattice and Structure modules. The Element and Molecule module is used to determine the radius of each of the atoms making up the material. Lattice and Structure modules use to define the structures of each material. Then input CIF data from $\mathrm{Fe}_{3} \mathrm{O}_{4}, \mathrm{MnFe}_{2} \mathrm{O}_{4}$ and $\mathrm{NiCo}_{2} \mathrm{O}_{4}$. The input data will provide information about the lattice parameters, the number of atoms and the volume.

In addition, it can be used to determine the primitive structure of each material. Then the result data enter in the crystal toolkit to determine the 3D structure image. The analysis was carried out by comparing the data with the results of the experiment research.

\section{RESULTS AND DISCUSSION}

The crystal structure of a material is usually described in the form of $3 \mathrm{D}$ balls and sticks or polyhedra depending on the crystal system [10]. Figure 1 is the result of modeling using the pymatgen module on $\mathrm{Fe}_{3} \mathrm{O}_{4}, \mathrm{MnFe}_{2} \mathrm{O}_{4}$ and $\mathrm{NiCo}_{2} \mathrm{O}_{4}$ materials. It can be seen that the three magnetic materials have the same structure, namely cubic spinel.

Based on the Figure $1 \mathrm{MnFe}_{2} \mathrm{O}_{4}$ and $\mathrm{NiCo}_{2} \mathrm{O}_{4}$ have similar structure, This is because both are included in the binary oxide group, which has two metals bonded to oxygen [11]. $\mathrm{Fe}_{3} \mathrm{O}_{4}$ has a very dense structure because there are two types of $\mathrm{Fe}^{2+}$ and $\mathrm{Fe}^{3+}$ atoms scattered in octahedral and tetrahedral sites [12].

Beside that in the pymatgen module the crystal structure data above can be used to search for the primitive structure of each material. The process for obtaining the primitive structure is described in Figure 2 .

Figure 3 shows the results of the modeling of the primitive structures of $\mathrm{Fe}_{3} \mathrm{O}_{4}, \mathrm{MnFe}_{2} \mathrm{O}_{4}$ and $\mathrm{NiCo}_{2} \mathrm{O}_{4}$. The primitive structure of the three materials is the same, which is included in the rhombohedral system [13].

The data of the crystal and primitive structures are compiled in Table 2. The data shows the lattice parameters $(a=b=c)$, angle and volume of each structures. The difference between the crystal and primitive structures of this model is in accordance with the experimental data that has been carried out previously [14]. The differences of lattice parameters between crystal and primitive structures of three materials shown in Figure 1 and Figure 3 are since primitive cells are the unit cells that make up the crystal structure [15]. So it can be seen that the lattice parameters of $\mathrm{Fe}_{3} \mathrm{O}_{4}, \mathrm{MnFe}_{2} \mathrm{O}_{4}$ and $\mathrm{NiCo}_{2} \mathrm{O}_{4}$ are larger than the lattice parameters of the primitive structure. A change in the lattice parameter will result a change in the volume of the structure. This is because the volume of crystal and primitive structures is the product of the multiplication of the lattice parameter [16]. The difference also occurs in the angles of the three magnetic materials, crystal structures included in the cubic spinel crystal system have an angle of $90^{\circ}$, while the primitive structures that are part of the rhombohedral system have an angle of $60^{\circ}$.

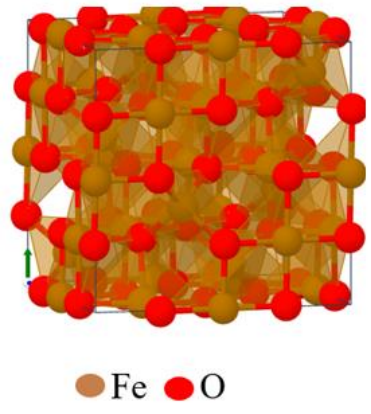

(a)

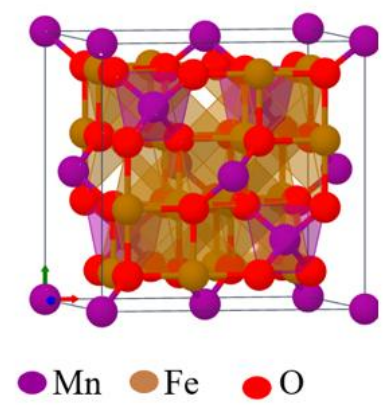

(b)

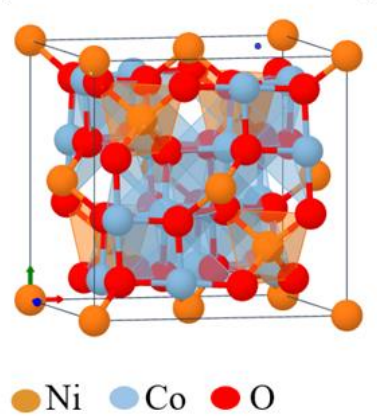

(c)

Figure 1 Crystal Structure of a) $\mathrm{Fe}_{3} \mathrm{O}_{4}$, (b) $\mathrm{MnFe}_{2} \mathrm{O}_{4}$ and (c) $\mathrm{NiCO}_{2} \mathrm{O}_{4}$.

In addition to identifying the crystal structure, there is a calculation using density functional theory (DFT) to determine the band structure of each material. Figure 3 shows the difference in the structural bands of $\mathrm{Fe}_{3} \mathrm{O}_{4}$, $\mathrm{MnFe}_{2} \mathrm{O}_{4}$ and $\mathrm{NiCO}_{2} \mathrm{O}_{4}$. Band structure is an important parameter in a material [17]. Knowing the band structure we can get information about electronic properties of the material such as the conduction band, valence band and band gap [18]. There are DOS 
Table 2. Data Output From Modelling Crystal and Primitive Structure

\begin{tabular}{|c|c|c|c|c|c|c|}
\hline & \multicolumn{3}{|c|}{ Crystal Structure } & \multicolumn{3}{|c|}{ Primitive Structure } \\
\hline & $\begin{array}{c}\text { Lattice } \\
\text { parameter (Á) }\end{array}$ & Angle $\left({ }^{\circ}\right)$ & Volume $\left(\AA^{3}\right)$ & $\begin{array}{c}\text { Lattice parameter } \\
(\tilde{A})\end{array}$ & Angle ( $\left.{ }^{\circ}\right)$ & Volume $\left(\AA^{3}\right)$ \\
\hline $\mathrm{Fe}_{3} \mathrm{O}_{4}$ & 8.3958 & 90 & 591.8154 & 5.9367 & 60 & 147.9538 \\
\hline $\mathrm{MnFe}_{2} \mathrm{O}_{4}$ & 8.5150 & 90 & 617.3819 & 6.0210 & 60 & 154.3455 \\
\hline $\mathrm{NiCO}_{2} \mathrm{O}_{4}$ & 8.2065 & 90 & 552.6802 & 5.8029 & 60 & 138.1701 \\
\hline
\end{tabular}

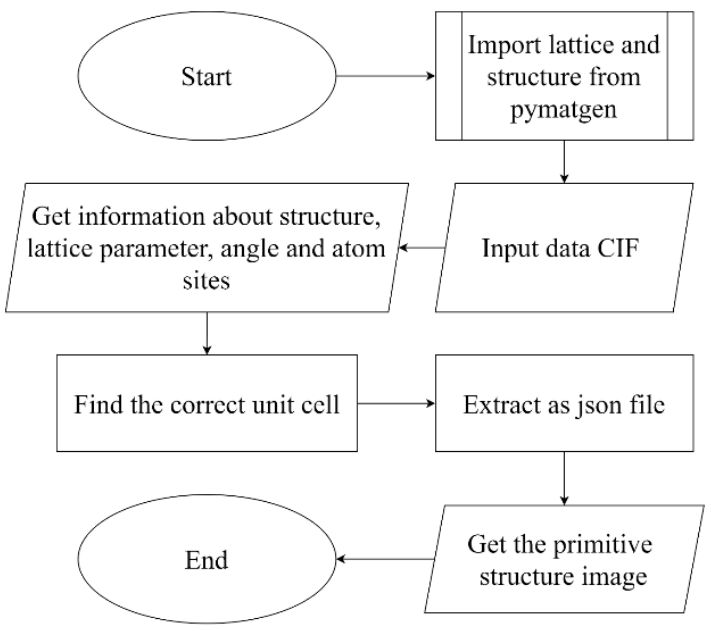

Figure 2 Flowchart of primitive structure.

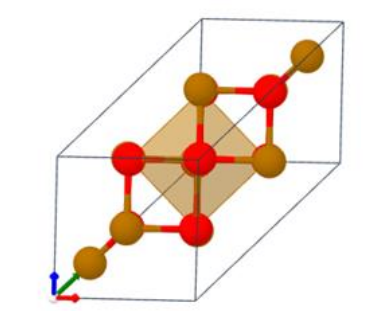

$\mathrm{Fe} O \mathrm{O}$

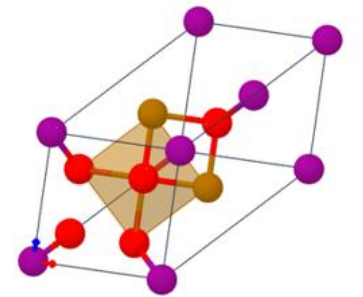

$\mathrm{Mn} \odot \mathrm{Fe} \odot \mathrm{O}$

(b) (a)

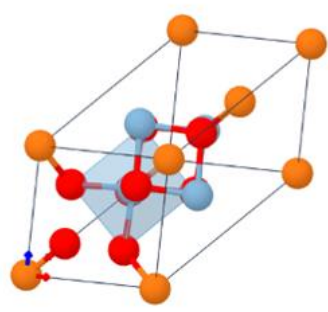

\section{$\mathrm{Ni} \odot \mathrm{Co} \odot$}

(c)

Figure 3 Primitive Structure of (a) $\mathrm{Fe}_{3} \mathrm{O}_{4}$, (b) $\mathrm{MnFe}_{2} \mathrm{O}_{4}$ and (c) $\mathrm{NiCO}_{2} \mathrm{O}_{4}$.
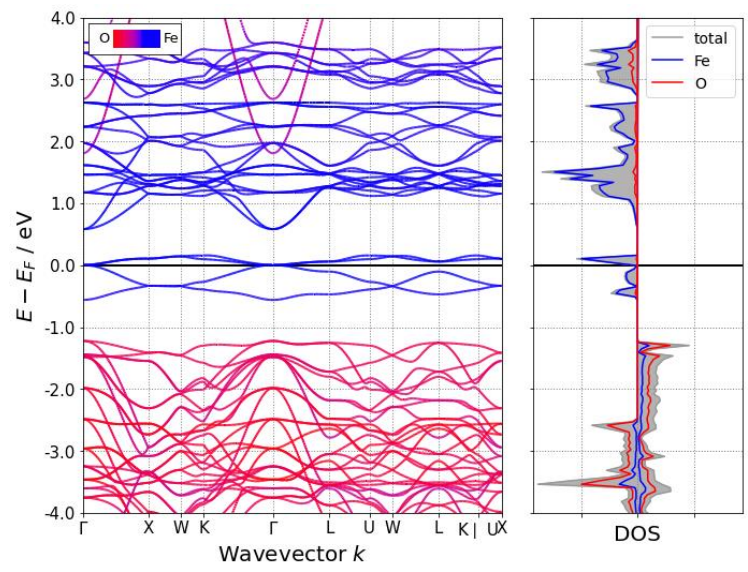

(a)

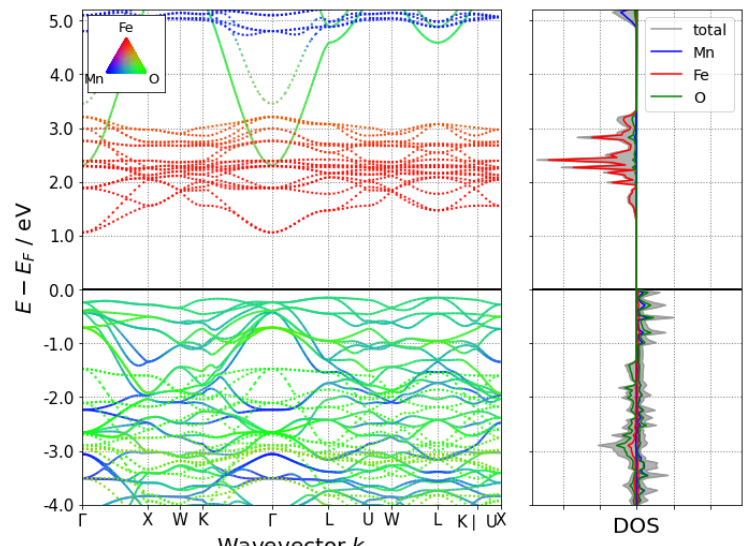

(b)

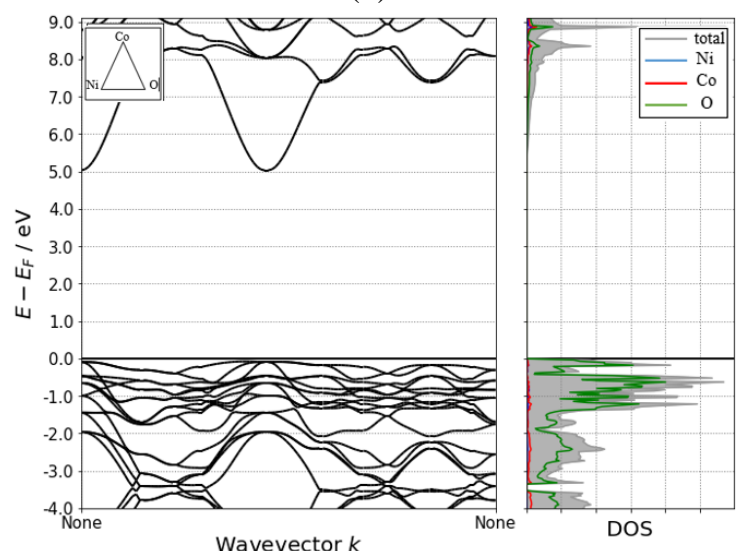

(c)

Figure 4 Band structure of a) $\mathrm{Fe}_{3} \mathrm{O}_{4}$, (b) $\mathrm{MnFe}_{2} \mathrm{O}_{4}$ and (c) $\mathrm{NiCO}_{2} \mathrm{O}_{4}$. 
(Density of State) which describes interband transitions and tabulate structural configuration [19].

The valence band is located at the bottom, while the conduction band is located at the top band structure. The difference between the three band structures lies in the distance formed between the valence band and conduction band due to the difference in ions that fill the octahedral part of each crystal structure. $\mathrm{NiCo}_{2} \mathrm{O}_{4}$ bandgap energy is higher than $\mathrm{Fe}_{3} \mathrm{O}_{4}$ and $\mathrm{MnFe}_{2} \mathrm{O}_{4}$ due to the presence of $\mathrm{Co}$ at the octahedral site, which is proven to increase the distance below the conduction band [19]. The band gap can be determined by looking at the distance formed between the conduction band and the valence band. The band gaps of $\mathrm{Fe}_{3} \mathrm{O}_{4}$, $\mathrm{MnFe}_{2} \mathrm{O}_{4}$ and $\mathrm{NiCo}_{2} \mathrm{O}_{4}$ are $2 \mathrm{eV}, 1.7 \mathrm{eV}$ and $5 \mathrm{eV}$, respectively. These results are in accordance with research both computationally and experimentally that have been carried out previously which stated that magnetic materials have a band gap in the range of 1.5$5 \mathrm{eV}$ with the highest band gap owned by $\mathrm{NiCo}_{2} \mathrm{O}_{4}$ magnetic materials [19-21].

\section{CONCLUSION}

The Research with a computational approach on $\mathrm{Fe}_{3} \mathrm{O}_{4}, \mathrm{MnFe}_{2} \mathrm{O}_{4}$ and $\mathrm{NiCo}_{2} \mathrm{O}_{4}$ magnetic materials was successfully carried out by using Google Colab and the pymatgen module. The results of the crystal structure modelling of the three materials show similarities with previous research, that is spinel cubic crystal structure with a combination of atoms between octahedral and tetrahedral parts. Then obtained the primitive rhombohedral structure of the three materials. Band structure calculation shows the band gap of each material is $2 \mathrm{eV}, 1.7 \mathrm{eV}$ and $5 \mathrm{eV}$. These results indicate that the pymatgen module is powerful to be used in computational modeling in materials science research.

\section{REFERENCES}

[1] J. H. Panchal, S. R. Kalidindi, and D. L. McDowell, "Key computational modeling issues in integrated computational materials engineering," Computer-Aided Design, vol. 45, pp. 4-25, 2013.

[2] R. de Borst, "Challenges in computational materials science: Multiple scales, multi-physics and evolving discontinuities," Computational Materials Science, vol. 43, pp. 1-15, 2008/07/01/ 2008.

[3] S. P. Ong, S. Cholia, A. Jain, M. Brafman, D. Gunter, G. Ceder, et al., "The Materials Application Programming Interface (API): A simple, flexible and efficient API for materials data based on REpresentational State Transfer (REST) principles," Computational Materials Science, vol. 97, pp. 209-215, 2015.
[4] S. P. Ong, W. D. Richards, A. Jain, G. Hautier, M. Kocher, S. Cholia, et al., "Python Materials Genomics (pymatgen): A robust, open-source python library for materials analysis," Computational Materials Science, vol. 68, pp. 314-319, 2013/02/01/ 2013.

[5] Z. Mo, C. Zhang, R. Guo, S. Meng, and J. Zhang, "Synthesis of $\mathrm{Fe} 3 \mathrm{O} 4$ nanoparticles using controlled ammonia vapor diffusion under ultrasonic irradiation," Industrial \& engineering chemistry research, vol. 50, pp. 3534-3539, 2011.

[6] J. Zhang, Y. Sun, X. Li, and J. Xu, "Fabrication of NiCo2O4 nanobelt by a chemical coprecipitation method for non-enzymatic glucose electrochemical sensor application," Journal of Alloys and Compounds, p. 154796, 2020.

[7] S. T. Yazdi, P. Iranmanesh, S. Saeednia, and M. Mehran, "Structural, optical and magnetic properties of $\mathrm{MnxFe3}-\mathrm{xO} 4$ nanoferrites synthesized by a simple capping agent-free coprecipitation route," Materials Science and Engineering: B, vol. 245, pp. 55-62, 2019.

[8] W.-Z. Yu, J.-A. Yan, and S.-P. Gao, "Band Gap Characters and Ferromagnetic/Antiferromagnetic Coupling in Group-IV Monolayers Tuned by Chemical Species and Hydrogen Adsorption Configurations," Nanoscale Research Letters, vol. 10, p. 351, 2015/09/04 2015.

[9] X. Gui and W. Xie, "Crystal Structure, Magnetism, and Electronic Properties of a RareEarth-Free Ferromagnet: MnPt5As," Chemistry of Materials, vol. 32, pp. 3922-3929, 2020/05/12 2020.

[10] A. D. Banadaki and S. Patala, "A threedimensional polyhedral unit model for grain boundary structure in fcc metals," npj Computational Materials, vol. 3, p. 13, 2017/03/27 2017

[11] G.-S. Jang, E.-B. Kim, M. S. Akhtar, H.-S. Shin, and S. Ameen, "An exploration of 3methoxypropionitrile chemical sensor based on layered hexagonal $\mathrm{NiCo} 2 \mathrm{O} 4$ nanoplates as electrode material," Ceramics International, 2021/02/15/ 2021.

[12] A. Nikmah, A. Taufiq, and A. Hidayat, "Synthesis and Characterization of $\mathrm{Fe} 3 \mathrm{O} 4 / \mathrm{SiO} 2$ nanocomposites," IOP Conference Series: Earth and Environmental Science, vol. 276, p. 012046, 2019/06/03 2019. 
[13] N. Taimoory, J. Trant, A. Rahdar, M. Aliahmad, F. Sadeghfar, and M. Hashemzaei, "Importance of the Inter-Electrode Distance for the Electrochemical Synthesis of Magnetite Nanoparticles: Synthesis, Characterization, Computational Modelling, and Cytotoxicity," eJournal of Surface Science and Nanotechnology, vol. accepted, 03/21 2017.

[14] C. Zhen, X. Zhang, W. Wei, W. Guo, A. Pant, X. $\mathrm{Xu}$, et al., "Nanostructural Origin of Semiconductivity and Large Magnetoresistance in Epitaxial NiCo2O4/A12O3 Thin Films," Journal of Physics D: Applied Physics, vol. 51, 02/27 2018 .

[15] M. O'Keeffe, "Aspects of crystal structure prediction: some successes and some difficulties," Physical Chemistry Chemical Physics, vol. 12, pp. 8580-8583, 2010.

[16] M. L. Bhatia, A. K. Singh, and T. K. Nandy, "Volume size factor and lattice parameter in cubic intermetallics with the L12 structure," Intermetallics, vol. 4, pp. 635-639, 1996/01/01/ 1996.

[17] J. Noh, O. I. Osman, S. G. Aziz, P. Winget, and J.-L. Brédas, "A density functional theory investigation of the electronic structure and spin moments of magnetite," Science and technology of advanced materials, 2014.

[18] A. Rowan, C. Patterson, and L. Gasparov, "Hybrid density functional theory applied to magnetite: Crystal structure, charge order, and phonons," Phys. Rev. B, vol. 79, 05/01 2009.

[19] D. Krishnan, L. Boddapati, P. Silwal, A. Gupta, and R. Datta, "Probing optical band gaps at nanoscale from tetrahedral cation vacancy defects and variation of cation ordering in $\mathrm{NiCo} 2 \mathrm{O} 4$ epitaxial thin films," Journal of Physics D: Applied Physics, vol. 47, p. 405001, 09/04 2014.

[20] P. M. Kouotou, A. E. Kasmi, L.-N. Wu, M. Waqas, and Z.-Y. Tian, "Particle size-band gap energy-catalytic properties relationship of PSECVD-derived Fe3O4 thin films," Journal of the Taiwan Institute of Chemical Engineers, vol. 93, pp. 427-435, 2018/12/01/ 2018.

[21] A. Jacintha, D. Manikandan, K. Chinnaraj, D. S. Arul Antony, and P. Neeraja, "Comparative Studies of Spinel MnFe2O4 Nanostructures: Structural, Morphological, Optical, Magnetic and Catalytic Properties," Journal of Nanoscience and Nanotechnology, vol. 15, 12/05 2015. 